\title{
Information Technology and SMEs in Pakistan
}

\author{
Irfan Ahmed \\ School of Management, Iqra University Islamabad \\ 5, Khayaban-e-Johar, H-9, Islamabad-44000, Pakistan \\ E-mail: irfisam@yahoo.com
}

Akmal Shahzad

School of Management, Iqra University Islamabad

5, Khayaban-e-Johar, H-9, Islamabad-44000, Pakistan

E-mail: everbrighter2011@gmail.com

Muhammad Umar

School of Management, Iqra University Islamabad

5, Khayaban-e-Johar, H-9, Islamabad-44000, Pakistan

E-mail: g_hafizumar_@yahoo.co.in

Dr Bashir Ahmed Khilji

National University of Modern Languages Islamabad, Pakistan

E-mail: kdrbashir@yahoo.co.in

\begin{abstract}
Recent, spectacular technological advances and break throughs have made the use of modern information technology a best competitive business tool. This study explores the use of IT by SMEs and their degree of satisfaction in using software and hardware. Results show that use of Word processing and spreadsheet is comparatively high. Use of communication software is very low. There is a dissatisfaction of respondents with software, more than hardware. One main reason is a lack of proper training as employees don't know how to use the software. Informal training methods like on-the-job training and open learning and training programmes etc. are very effective to train employees.
\end{abstract}

Keywords: Information technology (IT), Small to medium-sized enterprises, Hardware, Software, Training

\section{Introduction}

The rapid growth of technological innovations and the fusion of information technology has drastically changed the way companies compete. Many business enterprises are implementing the information technology for the purpose of gaining competitive advantage in their industry. In its various manifestations, IT processes data, gathers information, stores collected materials, accumulates knowledge and expedites communication (Chan, 2000). Gaining competitive advantage through the use of information technology requires business owners to have a firm grip over this vital corporate resource and manage its use (Beheshti, 2004).

Many factors influence the firm's competitiveness. However, most of the researchers since 1980 have examined the concept of IT as a powerful competitive factor for organization (Porter and Miller, 1985; Clemons and Row, 1991; Barney, 1999). IT, in its nascent business world form, was generally considered a support tool. However, as time passed and technological sophistication grew, IT's usage and impact increased dramatically (Chan, 2000). This pattern of progress may be due to the advancement of technology. A technological diffusion or infusion may be attributable to the fact that IT's introduction into an organization creates a further technological needs and encourages product and policy innovation to meet such needs.

It is very difficult to clearly distinguish between small, medium, and large firms. Researchers distinguish between SMEs and large corporations on the basis of employees, sales volume, and value of assets. Although the most common way to determine whether a business is small medium, or large, is by number of employees, there 
is not an exact threshold that make a distinction between SMEs and large businesses based on the number of employees. However, small and medium sized companies are often considered having less than 500 employees (Hakserver, 1996; van der Wiele and Brown, 1998). In addition, some of the characteristics that separate small and medium sized businesses from large organizations are (Hakserver, 1996): ownership, management and organizational structure; capital resources; objectives; markets; and customers.

IT is recognized as a viable, competitive actor via increased productivity, better profitability, and value for customers (Hitt and Brynjolfsson, 1996). Role of IT in competitiveness has been primarily focused on large organizations. However, in today's global market, and in the era of e-commerce, small and medium size enterprises (SMEs) can employ IT to increase their competitive position along with their large counterparts (Beheshti, 2004). Barau et al. (2001) showed that small businesses were utilising the Internet more than their counterparts. In order to take full advantage of IT and to compete in the global business environment, top executives must recognize the strategic value of IT and exploit it.

Despite the significant contribution that IT has made to business, many studies indicate that there are a large number of unsuccessful IT implementations in SMEs and that the adoption rate is very slow (Acar et al., 2005; Shin, 2006). Researches give three main reasons for this. First, management doesn't know or is unclear on how and why their firms adopt IT in the first place (Levy et al., 2001). Second, there is a misconception toward the IT adoption process mainly because managers do not understand the relationship between IT and the firms themselves (Bull, 2003) or are uncertain about the opportunities that IT can offer (Southern and Tilley, 2000). Finally, firms do not have the capabilities to expand their IT resource (Acar et al., 2005; Claessen, 2005) because of lack of business and IT strategy, limited access to capital resources, emphasis on automating, influence of major customers and limited IS skills (Ballantine et al., 1998; Bhagwat and Sharma, 2007; Bruque and Moyano, 2007).

The state of SMEs in Pakistan is very interesting. SMEs play a very significant role in the economy of Pakistan. These constitute nearly $90 \%$ of all the enterprises in Pakistan; employ $80 \%$ of the non-agricultural labor force; and their share in the annual GDP is $40 \%$, approximately (SMEDA, 2010). Infat, the rate of adoption and utilization of IT by SMEs is slow but it is increasing with the passage of time as more and more SMEs are realizing the importance of IT.

Purpose of this paper is to investigate the degree of satisfaction of SMEs with the use of IT i.e. software and hardware. Rest of the paper is set as follows: section 2 describes the research methodology; section 3 shows the findings; section 4 and 5 depict the conclusion and limitation respectively.

\section{Research Methodology and Sample Size}

A questionnaire based survey was conducted into the use of computers in small businesses. A related research has been done by SBRT (Small Business Research Trust) in 1991 and by Mitev and Marah in 1998. Questionnaire of the research was developed by considering study of Mitev and Marah. The instrument consisted of 13 questions. This instrument was presented to 3 scholars for the review. After few suggestions given by them, amendments were made and then it was finalized. Due to time constraint, face-to-face interviews were carried out with owner-managers. The same questions were used as a basis for the semi-structured interviews and the material gathered enriched the questionnaire results qualitatively.

Responses were from companies employing less than 100 people. This study included 90 SMEs from Rawalpindi, Islamabad and Wah Cantt. It was envisaged that there might have been differences in responses between the very small companies (one or two staff) and slightly larger ones. On analysis, the differences proved insignificant and no apparent trends were found. The questionnaire inquired about IT usage and degree of satisfaction or dissatisfaction on the software and hardware.

\section{Findings}

In the survey, only 15 respondents out of 90 did not currently have computers installed. Computer hardware had been used for an average of 5 years with a range of 1 to 10 years. When asked to rank their degree of satisfaction with computer hardware and software the results in Table 1 are obtained. It is interesting to note that there is some degree of dissatisfaction in the use of both computer software and hardware, this dissatisfaction is more marked in the area of computer software. This is perhaps not surprising given the range of products, which may also give rise to expectations. Making decisions about software may be becoming more complex and risky. Most respondents said that employees could not use the software packages properly. Moreover, there was not a proper training facility available to them. All these trends may explain why there is no 'very satisfied' respondent. 
Respondents were asked about their software usage and the results are illustrated in Figure 1. The graph illustrates that the new trends are emerging such as the use of integrated and presentation packages. It also shows that there is comparatively small growth in communication technology. The adoption of word processing software and spreadsheet is particularly high.

\section{Conclusion}

This study finds out that operational applications such as word processing, databases and spread sheets are used more widely by the SMEs. However, there is still dissatisfaction with purchasing software, and there is a strong need for advice with purchasing software, and there is a strong need for the advice provided by concerned parties other than vendors. Requirements analysis should be supported by a feasibility study, which is still a poorly understood the concept by many owner-managers. Suggestions by Levy et al (1997) include a more proactive approach from the software provider who would review strategy with the company and advise on future IT requirements; bring in a consultant to act as an intermediary; ensure that one person has responsibility for reviewing IT needs and liaising with the software provider.

The majority of SMEs has not advanced to a stage where telecommunications and interconnectivity are seen as important, although there has been growth in this area. Only 40 percent has communication softwares. Some respondents said that employees could not use the software properly. Although most small businesses surveyed acknowledged that work practices must change if IT is to be used effectively, few considered the effects on jobs, skills and training before implementing IT. Those small firms who knew where to get training advice were not satisfied with the training provided. Employees need and informal training methods such as on-the-job training, open learning and training programmes which integrate both technical and managerial aspects. Moreover, successful management training also requires an environment of business growth (Marshall et al, 1995).

\section{Limitations}

Time constraint was a major limitation as the whole project had to be completed within a term. Sample size was limited. Had the survey been conducted on many other SMEs, results could have been more conclusive. The research was conducted in Islamabad, Rawalpindi and Wah Cantt. For a more generalized perception, this research should be conducted in other cities as well.

\section{References}

Acar, E., Koc,ak, I., Sey, Y. and Arditi, D. (2005). Use of information and communication technologies by small and medium-sized enterprises (SMEs) in building construction, Construction Management and Economics, Vol. 23 No. 7, pp. 713-22

Ballantine, J., Levy, M. and Powell, P. (1998). Evaluating information systems in small and medium-sized enterprises: issues and evidence, European Journal of Information Systems, Vol.7 No.4, pp.41-51

Barney, J. (1999). Firm resources and sustained competitive advantage, Journal of Management, Vol. 17 No. 1, pp. $99-120$

Beheshti, H.M.( 2004). The Impact of IT on SMEs in the United States, Information Management and Computer Security, Vol.12 No.4, pp. 318-327

Bhagwat, R. and Sharma, M.K. (2007). Information system architecture: a framework for a cluster of small and medium-sized enterprises (SMEs). Production Planning and Control, Vol. 18 No. 4, pp. 283- 96

Bruque, S. and Moyano, J. (2007). Organisational determinants of information technology adoption and implementation in SMEs: the case of family and cooperative firms, Technovation, Vol. 27 No. 5, pp. 241-53

Bull, C. (2003). Strategic issues in customer relationship management (CRM) implementation, Business Process Management Journal, Vol. 9 No. 5, pp. 592-602

Chan, S.L., 2000, Information Technology in Business Processes, Business Management Journal, Vol 6 No. 3 , pp.224-237

Claessen, E. (2005). Strategic use of IC reporting in small and medium-sized IT companies: a progress report from a Nordic project, Journal of Intellectual Capital, Vol. 6 No. 4, pp. 558-69

Clemons, E. and Row, M. (1991). Sustaining IT advantage: the role of structural differences, MIS Quarterly, Vol. 15 No. 3, pp. 257-92

Hakserver, C. (1996). Total quality management in the small business environment, Business Horizons, Vol. 39 No. 2, pp. 33-41 
Hitt, L. and Brynjolfsson, E. (1996). Productivity business profitability, and consumer surplus: three different measures of information technology value, MIS Quarterly, Vol. 20 No. 2, pp. 121-43.

Levy, M., Powell, P., Merali, Y. and Galliers, R. (1997). Assessing information systems strategy development frameworks in SMEs, in R. Galliers, S. Carlsson, C. Loebekke, C. Murphy, H. R. Hansen and R. O'Callaghan (eds) Proceedings 5th European Conference on Information Systems, University College Cork, Cork, Ireland, 553-569

Levy, M., Powell, P. and Yetton, P. (2001). SMEs: aligning IS and the strategic context, Journal of Information Technology, Vol. 16 No. 3, pp. 133-44

Marshall, J. N., Alderman, N., Wong, C. and Thwaites, A. (1995). The impact of management training and development on small and medium enterprises, International Small Business Journal, 13(4). 73-91

Mitev, N.N. and Marah, A.E. (1998). Small Businesses and Information Technology: Risk, Planning and Change, Henry Stewart Publications, ISSN 1462-6004, 228-245

Porter, M. and Miller, V. (1985). How information gives you competitive advantage, Harvard Business Review, Vol. 63 No. 4, pp. 149-60

Small Business Research Trust (SBRT) (1991). Quarterly survey of small businesses in Britain, No 2, National Westminster and Small Business Research Trust, Open University School of Management, Milton Keynes

SMEDA Pakistan (2010). Retrieved from http://www.smeda.org.pk/main (Aug 20, 2010)

Shin, I. (2006). Adoption of enterprise application software and firm performance, Small Business Economics, Vol. 26 No. 3, pp. 241-56

Southern, A. and Tilley, F. (2000). Small firms and information and communication technologies (ICTs): toward a typology of ICTs usage, New Technology, Work and Employment, Vol. 15 No. 2, pp. 138-54

Van der Brown, A. and Wiele, T. (1998). Venturing down the TQM path for SMEs, Total Quality Management, Vol. 16 No. 2, pp. 50-69

Table 1. Degree of satisfaction of computer hardware/software:

\begin{tabular}{|l|c|c|}
\hline & Percent of firms \\
\hline Satisfaction & 0 & Software \\
\hline Not satisfied & 15 & 0 \\
\hline Not entirely satisfied & 75 & 35 \\
\hline Satisfied & 10 & 45 \\
\hline More than satisfied & 0 & 20 \\
\hline Very satisfied & 0 \\
\hline \multicolumn{2}{|l|}{ Note: There were 75 respondents in each category } \\
\hline
\end{tabular}

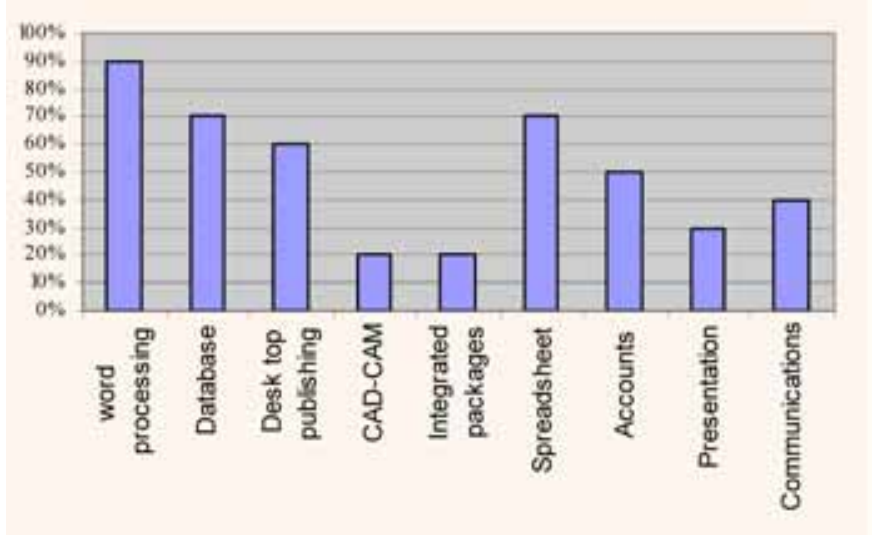

Figure 1. Percentage of Software Used 